\title{
PERCEPTION OF WOMEN OF CHILDBEARING AGE ON EARLY \\ DETECTION OF CERVICAL CANCER WITH IVA TEST IN THE \\ BASIC ESSENTIAL NEONATAL OBSTETRICS SERVICES \\ CIPEUNDEUY COMMUNITY HEALTH \\ CENTER SUBANG REGENCY
}

Wiwin Elis Sumarni, Lia Nurcahyani

Poltekkes Kemenkes Tasikmalaya

lianurcahyani17@gmail.com

\begin{abstract}
Cervical cancer is the most common cancer in women with an estimated 570,000 new cases in 2018 and represents $6.6 \%$ of all cancers in women. The behavior of women of childbearing age in preventing cervical cancer with early detection is still low. Nationally, it is still less than 5\%, while the target to be achieved in 2019 is 50\%. In Subang Regency in 2019, of the target of 7500, only 20 people $(0.27 \%)$ did IVA tests (Subang District Health Office, 2019). This study aims to determine the perception of women of childbearing age on early detection of cervical cancer with IVA test in the Basic Essential Neonatal Obstetrics Services Cipeundeuy Community Health Center, Subang Regency In 2020. This research is qualitative with a case study approach, the research subjects are 5 women of reproductive age. Measurement and observation of these variables using in-depth interviews. Data analysis through transcription, reduction, categorization, presentation of data in narrative form. The behavior of women of childbearing age in preventing cervical cancer with early detection is based on the perception of vulnerability of women of childbearing age to feel vulnerable to cervical cancer, because women of childbearing age is already active in sexual intercourse, based on the perception of severity seriousness. Women of childbearing age considers cervical cancer a serious disease, based on the perceived advantage that this examination is to determine the health condition of the presence of signs and symptoms, based on the perception of obstacles due to shame, fear, lack of knowledge and costs. Women of childbearing age perception of cervical cancer early detection includes perception of vulnerability, perception of severity/ seriousness, perception of benefits and perception of barriers.
\end{abstract}

Keywords : Perception of women of childbearing age; IVA test; and Cervical Cancer 


\section{Introduction}

Cervical cancer is the most common cancer in women with an estimated 570,000 new cases in 2018 and represents $6.6 \%$ of all cancers in women. About $90 \%$ of deaths from cervical cancer occur in low and middle income countries (World Health Organization (WHO), 2018).

Globocan data states that in 2018 there were 18.1 million new cases with a death rate of 9.6 million deaths, where 1 in 5 men and 1 in 6 women in the world experienced cancer. The data also states that 1 in 8 men and 1 in 11 women die from cancer. The incidence of cancer in Indonesia (136.2 / 100,000 population) ranks 8th in Southeast Asia, while in Asia it is 23rd (RI Ministry of Health, 2015b).

The government has attempted cervical cancer screening through the 2015 National Program for the Prevention and Detection of Cervical Cancer and Breast Cancer. That women must be well aware of the importance of cervical cancer prevention. Prevention itself can be done either primary or secondary. Primary prevention of cervical cancer is by HPV vaccination and secondary prevention is examination and IVA tests PAP smear (RI Ministry of Health, 2015b).
Research conducted by the Division of Gynecological Oncology, Department of Obstetrics and Gynecology, FKUI at Dr. Cipto Mangunkusumo from January 2006 to December 2010, it was found that the age range of patients with cervical cancer was 51.42 years (21 - 85 years). Most of the incidence occurred in the age group 35 64 years $(87.3 \%)$, with a peak in the age group 40 - 59 years $(71.3 \%)$, while the age group 65 - 69 years (5.4\%), age 70 - 74 years $(2.5 \%)$.

Based on this, screening can be carried out at the age of $20-74$ years, however the priority of the screening program in Indonesia is for women aged 30-50 years (RI Ministry of Health, 2015a)

The behavior of women of childbearing age in preventing cervical cancer with early detection is still low. This behavior is influenced by the perception and belief factors of women with low cervical cancer (Oktaviana, 2015).

Perception is the process of receiving stimuli through the five senses which is preceded by attention so that individuals are able to know, interpret and appreciate things that are in the neighborhood around (Saudah \& Yuniarti, 2019). 
This is in accordance with the theory of the Health belief model which was first developed in the 1950s by social psychologists Hochbaum, Rosenstock, and Kegels who worked at Service HealthUnited States society. Health belief model is a concept that reveals the reasons for individuals to want or not to do behaviorhealthy (Pratiwi, 2018).

Based on research in Kediri, research on the perception of women of childbearing age on early detection using IVA in the work area of the Sukorame Kediri Community Health Center on 120 respondents in 2016. The research describes 5 domains including perceived susceptibility, perceived severity, perceived benefits, perceived barriers, and cues to action. The results of the research on the domain of perceived susceptibility show that the perception of women of childbearing age in that area is low as much as $61.2 \%$, low perceived severity is $66.7 \%$, low perceived benefits are $60 \%$, high perceived barrier is $52.5 \%$ and cues to action with a high yield of $53.3 \%$ (Purwati \& Janes, 2017).

Other research in Banyuwangi, East Java on 140 women of childbearing age in 2015 also shows the same thing. Perceived susceptibility of women of childbearing age is low with $21.2 \%$ results, $19.4 \%$ perceived severity, $20.09 \%$ perceived benefits and 79.68\% perceived barrier (Wigati, 2016).

One of the health centers with a decreased interest in women of childbearing age participation in conducting the IVA test was the PONED Cipeundeuy Health Center. In 2018 the number of women aged $30-50$ years as the target was 7,060 people and 31 people who carried out the IVA test $(0.44 \%)$ (Subang District Health Office, 2018). Furthermore, in 2019 the target number of women aged 30- 50 years is 7,500 people and 20 people who carry out IVA tests (0.27\%) (Subang District Health Office, 2019).

Based on the data above, the majority of women of childbearing age in the work area of the PONED Cipeundeuy Community Health Center did not perform IVA tests, so the researcher felt the need to conduct a study entitled Perceptions of women of childbearing age about early detection of cervical cancer with IVA tests in the Puskesmas working area. PONED Cipeundeuy, Subang Regency.

The formulation of the problem in this study is what is the perception of women of childbearing age about early detection of cervical cancer with IVA tests 


\section{DOI: $10.34305 /$ gemic.v1i1.308}

in the PONED Cipeundeuy District Health

Center Work Area in 2020.

\section{Method}

This research is qualitative witha case study approach that can determine the perceptions of women of childbearing age on the IVA test. In case study research, researchers carefully investigate a program, event, activity, process or group of individuals (Cresswell, 2019).

This research was conducted in the working area of the PONED Cipeundeuy Health Center, Subang Regency, because the majority of women of childbearing age did not participate in the IVA examination in the area. The research was conducted in May 2020 to July 2020. During the pandemic, initially the researcher wanted to do research online via WhatsApp, the results of the interview were recorded and recorded, but because of something, the researcher conducted door-to-door research delivered by cadres, the results of the interview were written and recorded. Prior to that the researcher had received permission from the health center to conduct door-to-door research because at that time it was supported by the results of Covid-19 monitoring that Subang Regency was in a low risk zone for Covid-19, therefore the researcher conducted door-todoor research and remained using health protocols (Saefullah, 2020).

The sampling technique used snowball sampling. The research subjects were 5 women of childbearing age people. Measurement and observation of this variable using in-depth interviews. Data analysis through transcription, reduction, categorization, presentation of data in narrative form.

\section{Result}

The subjects in this study were women women of childbearing age who are married 30-50 years old who have sexually active sex and who have not done IVA tests in their work area Puskesmas PONED Cipeundeuy.

\section{Evaluation result}

1. Cervical cancer in the area of the female organs.

2. Signs and symptoms: pain during intercourse, unusual, smelly, or abnormal mucus.

3. Cervical cancer is dangerous until death

4. Cervical cancer is very vulnerable to all women.

5. The causes of cervical cancer are less than 20 years of age and multiple partners.

1. Cervical cancer is a serious disease.

2. The IVA test is mandatory for women who have had sexual intercourse.
Vulnerability

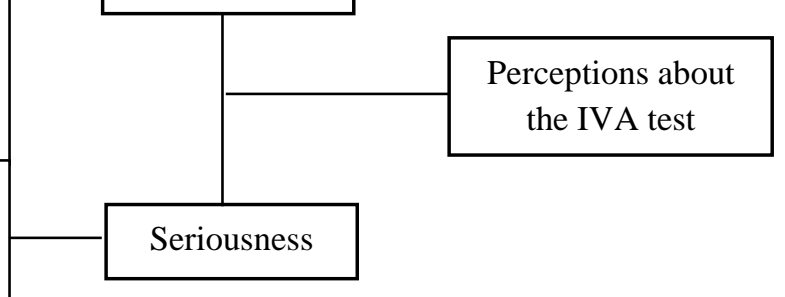


1. The IVA test is very useful. Because to know the signs and symptoms of cervical cancer.

2. Not all informants know that there has been any counseling about cervical cancer.

3. Useful if there is counseling on early detection of cervical cancer.

Because of fear, lack of knowledge, shame and expensive fees.

\section{Discussion}

1. Perceived of Vulnerability

Women of childbearing age said that cervical cancer is dangerous until death. This can be seen from the following statement:

“... It's dangerous to die, if you don't get caught, you know it's the final stage. Sometimes people don't realize that he's sick .. " $(S 1)$

“... Danger of causing death ..” (S2)

"... In having a relationship, it often hurts to the point of death ...." (S3)

“... .. Danger, can cause death, like Jwho was caught in the final stage and died. " (S4) $\&$ (S5)

The results of this study women of childbearing age have less knowledge of cervical cancer. They know that cervical cancer is cancer in the female organs and just know that in the news there are artists who have cervical cancer and have died. Because of this, women of childbearing age realizes that cervical cancer is dangerous and can cause death. As well as realizing that cervical cancer is vulnerable to all women who have had sexual intercourse. This can be seen from the following questions:

... "It could be, especially if the woman works in shifts, or works at night ..." (S4)

".....Yes are very vulnerable ..." (S5)

The information obtained at the informant's level of understanding is as follows:

“...... Change partner....” (S4)

"... maybe having sex at the age of less than 20 years and changing partners ..." (S5)

Based on the results of this study, women of childbearing age felt vulnerable to cervical cancer, because women of childbearing age was already active in sexual intercourse and an unhealthy lifestyle. women of childbearing age who feel vulnerable do not necessarily want to do the test, so there are supporting factors 
for women of childbearing age willingness to be tested.

This research is not in line with the results of research conducted by Sahr \& Kusumaningrum (2018) showing that most women women feel that they are not susceptible to cervical cancer because according to them they have never performed risky behavior that triggers cervical cancer (Sahr \& Kusumaningrum, 2018).

\section{Perception of seriousness / severity}

Based on the results of in-depth interviews, information was obtained that cervical cancer is a serious disease. This is obtained from the following statement:

"... cervical cancer. Serious disease .." $(S 1, S 2, S 3, S 4, \& S 5)$

Based on the above, cervical cancer is serious, therefore, women of childbearing age said that the IVA test is very important to do because of the following:

“...... Actually it's important, it just depends on the individual, there are those who are brave and some are afraid, mostly afraid, what will I do later, because I don't know because I also lack knowledge. Even though it's good because we know ohh Alhamdulillah we are healthy. Can continue to the next stage which is PAP Smear. .. "(S1)

"........ Important, let us know, knowing we have symptoms of cervical cancer ...." $(S 2)$

"... Important, in order to know the health condition of women who have had intercourse ...." (S3)

"... .. It's very important, to know more about cervical cancer in all women, to know more clearly, to know more about the dangers of cervical cancer in women...." (S4)

"... It is important, so that the disease is caught ..." (S5)

Perceived severity is the level of one's belief that the consequences of the problem healthwhich will get worse (Manuntung \& Kep, 2018). Perception of severity is a consideration of the level of seriousness of a threat, the more serious the threat of disease isthe morestrong urge for someone to act to avoid it (Wigati, 2016). According to the results of this study, women of childbearing age considers that cervical cancer is a serious disease, so that the IVA test is important because it can 
identify the signs of symptoms that are present.in the female reproductive organs.

3. Perception of benefits

Perception of advantages according to the informant, the results of the IVA test were useful, to determine the conditionhealth the presence of signs and symptoms of cervical cancer.

This study is in line with the results of research by Sahr \& Kusumaningrum (2018), namely that most women of childbearing age think that it is the advantage of doing so IVA test is in order to immediately know the condition healthpotentially cervical cancer or not so that it can immediately take further action or take precautions. This research is in line with that theoryPerceived benefits are positive outcomes that someone believes are results and actions (Manuntung \& Kep, 2018).

4. Perception of Barriers

Based on the results of the interview, the following obstacles were found:

“... Afraid, don't know the same place, embarrassed too. If For example, if someone has scheduled it, I'm ready Insha Allah want.... "(S1)

“...... Shame..heheee just scared...” (S2)
“..... Because it's not ready to do the IVA test yet. Yesterday, he called him to hurry home .... "(S3)

“...... First, I don't know much more, continue to pay for the obstacles expensive or pay it myself, especially those who don't have BPJs like to pay more, shame, fear. If you have tested you, you will find the symptom detection, I'm afraid when you do the test you know I got it so I'm depressed. "(S4)

“...... Afraid of getting caught....” (S5)

Women of childbearing age said the response of her husband and other members to the IVA test was as follows:

"... The response of husband and family: just pretentious as long as it's good, or good for his health, it's up to you, if you want to be pretentious if not it's fine ..."

"... The response of husband and family: $\operatorname{good} \ldots . . . "(S 2)$

“... Suggesting ..” (S3)

"... If maybe it's good for me why not ..." (S4)

"... .Yes well .." (S5) 


\section{DOI: $\underline{10.34305 / g e m i c . v 1 i 1.308}$}

“.....Supports...” (S1, S2, S3, S4, S5)

Based on the results of the interview, it was concluded that women of reproductive age did not want to do the IVA test because of fear and lack of knowledge, embarrassment and high costs. The point of one of the informants' statements that only having a BPJS is already expensive, let alone the public paying. Then the response of the husband and other family members was good and supportive of positive activities, namely the IVA test.

Therefore, the majority of women in the working area of the PONED Cipeundeuy Community Health Center do not want to do IVA tests even though their husbands and other family members are very supportive of early detection of cervical cancer. If from the heart there is no will, even though outsiders support it, there will still be no willingness to do it.

The results of this study are in accordance with the theory of perceived barriers (Perceived barrier), which is the perceived barrier in the form of perceptions of unavailability, inconvenience, cost, difficulty, or time spent from an activity (Malehere, 2019).

This is in line with the research stated by Yuliwati (2012), the results of the study showed that some women of childbearing age in the Prambon Health Center area had less behavior in early detection of cervical cancer using the IVA test method, namely $58.5 \%$ (Jannah \& Astuti, 2017).

This is in line with research conducted by Oktaviana (2015). The results obtained in 4 perception domains are low. Perceived susceptibility is low with a mean result of $21.2 \%$. Low perceived severity with a mean yield of $19.41 \%$. Perceived benefit is low with an average yield of $20.09 \%$. High perceived barrier with a result of $79.66 \%$ (Oktaviana, 2015).

Perceived barrier is a negative result that is believed to be the result of an action (Manuntung, 2018). This theory is supported by the results of Crystianty's (2018) research, namely the perception of women of reproductive age couples about IVA in the Pulorejo Health Center, Jombang Regency, mostly having negative perceptions (Crystianty, 2018).

The perception of obstacles obtained from this study are costs that are not in accordance with the economic conditions of the community, the inconvenience of having to do an examination because they have to open their pants and a person's low knowledge of the factors that can increase 
the risk of developing cervical cancer can be caused by the low information someone gets about cervical cancer risk. For this reason, increasing the provision of information about cervical cancer needs to be developed by implementing several programs in each government agency.

\section{Conclusion}

1. Based on the perception of seriousness / severity, women of childbearing age considers that cervical cancer is a serious disease, so the presence of an IVA test is important because it can identify the signs of symptoms that occur. in the female reproductive organs.

2. Based on the perception of vulnerability, women women feel vulnerable to cervical cancer, because women are already active in having sexual intercourse and a lifestyle that is not healthy. Women of childbearing age who feel vulnerable do not necessarily want to do the test, so there are supporting factors for women of childbearing age willingness to be tested.

3. Based on the perception of benefits, women of childbearing age performed an IVA test, which was to determine the condition health the presence of signs and symptoms of cervical cancer.

4. Based on the perception of obstacles, women of childbearing age do not want to do the IVA test obtained because of fear and lack of knowledge, embarrassment and expensive costs.

\section{Suggestion}

1. For puskesmas

a. Policy Determinants

It is hoped that policy makers at the PONED Cipeundeuy Puskesmas will consider the cost of conducting early detection of cervical cancer by IVA tests because there are still many women of childbearing age who complain of the cost of the examination.

b. For midwives

It is hoped that the executive officer in the field to increase the socialization of the early cervical cancer detection program with the IVA test method with counseling, because seen from the results of this study, many women of childbearing age still do not understand about IVA tests and health workers can invite women of childbearing age to want to do an examination. 
2. For further researchers It is expected to be able to research with different methods with a larger number of samples.

\section{Reference}

Journal:

Crystianty, N. (2018). The Relationship between Perceptions of Women in Fertile Age Couples about Visual Inspection of Acetic Acid and the motivation for IVA examination. STIKes Insan Cendekia Medika Jombang.

Jannah, M., \& Astuti, M. D. P. (2017). Behavior of women of childbearing age in conducting IVA tests at UPTD Puskesmas Pondok Gede, Bekasi City in 2017. Journal of Health Science, 11(9), 1689-1699.

Purwati, H., \& Janes, C. (2017). The Perception Of Fertile Age Women, On Early Detection Of Ca. Cervical With Visual Inspection With Acetic Acid Method At Bpm Hj. Dyah Indrawati, Sst, Tanjangrono Village, District Ngoro, Mojokerto. 15.

Sahr, L. A., \& Kusumaningrum, T. A. I. (2018). Perception and Behavior of Fertile Age Women in Conducting a Visual Inspection Test for Acetic Acid. Indonesian Journal of Health Promotion, 13(2), 114-128.

Saudah, N., \& Yuniarti, E. V. (2019). Relationship between Family Social Support and Perceptions of Fertile Age Women in Iva Examination (Visual Inspection of Acetic Acid) and Cervical Cancer Incidence.
Journal of Chemical Information and Modeling.

Wigati, P. W. (2016). Pathway Analysis with the Health Belief Model on the Use of Acetic Acid Visual Inspection Screening for Early Detection of Cervical Cancer in Women of Fertile Age in Kota Kediri. 19(8).

Text Book:

Cresswell, J. W. (2019). Research Design Approaches to qualitative, quantitative and mixed methods. Yogyakarta: Pustaka Belajar.

Manuntung, N. A., \& Kep, M. (2018). Cognitive Behavior Therapy in Hypertensive Patients. Wineka Media.

RI Ministry of Health. (2015a). Cancer Bulletin Data and Information Center. RI Ministry of Health.

RI Ministry of Health. (2015b). Permenkes RI Number 34 Handling Breast and Cervical Cancer. RI Ministry of Health.

Subang District Health Office. (2018). Profile of the Subang District Health Office in 2018. Subang District Health Office.

Subang District Health Office. (2019). Profile of the Subang District Health Office in 2019. Subang District Health Office.

\section{Thesis / Disertation:}

Malehere, J. (2019). Analysis of Cervical Cancer Prevention Behavior in Women in Fertile Age Couples based on Health Promotion Theory. 
Airlangga University.

Oktaviana, M. (2015). Relationship Between Perceptions of Individual Vulnerability, Severity of Disease, Benefits and Barriers with Use of Visual Inspection Screening for Acetic Acid in Women of Fertile Age. Sebelas Maret University.

Pratiwi, K. N. (2018). Determinants of Fertile Age Women's Participation in Visual Inspection of Acetic Acid (IVA) for Early Detection of Cervical Cancer Using the Health Belief Model (HBM) (Study in the Work Area of Kertosari Health Center). University of Jember.

\section{Website:}

Saefullah, R. (2020). Subang Enter the Covid-19 Low Risk Zone: Economic News Portal. https://www.wartaekonomi.co.id/read 295894/alhamdulillah-subang-masukzona-risiko-rendah-covid-19

World Health Organization (WHO). (2018). Cervical Cancer. http://www.who.int/cancer/prevention /diagnosisscreening/cervicalcancer/en // 